\title{
Transparent Wood for Thermal Energy Storage and Reversible Optical Transmittance
}

\author{
Céline Montanari, ${ }^{\dagger}$ Yuanyuan $\mathrm{Li}^{\dagger}{ }^{\dagger}$ Y Hui Chen, ${ }^{\dagger}$ Max Yan $^{\dagger}{ }^{\dagger}$ and Lars A. Berglund ${ }^{*},{ }^{\dagger}$ \\ ${ }^{\dagger}$ Department of Fiber and Polymer Technology, Wallenberg Wood Science Center, KTH Royal Institute of Technology, \\ Teknikringen 56, 10044 Stockholm, Sweden \\ ${ }^{*}$ Department of Applied Physics, KTH Royal Institute of Technology, Isafjordsgatan 22, 16440 Kista, Sweden
}

Supporting Information

ABSTRACT: Functional load-bearing materials based on phase-change materials (PCMs) are under rapid development for thermal energy storage (TES) applications. Mesoporous structures are ideal carriers for PCMs and guarantee shape stability during the thermal cycle. In this study, we introduce transparent wood (TW) as a TES system. A shape-stabilized PCM based on polyethylene glycol is encapsulated into a delignified wood substrate, and the TW obtained is fully characterized, also in terms of nano- and mesoscale structures. Transparent wood for thermal energy storage (TW-TES) combines large latent heat $\left(\sim 76 \mathrm{~J} \mathrm{~g}^{-1}\right)$ with switchable optical transparency. During the heating process, optical transmittance increases by $6 \%$ and reaches $68 \%$ for $1.5 \mathrm{~mm}$ thick TW-TES. Characterization of the thermal energy regulation performance shows that the prepared TW-TES composite is superior to normal glass because of the combination of good heat-storage and thermal insulation

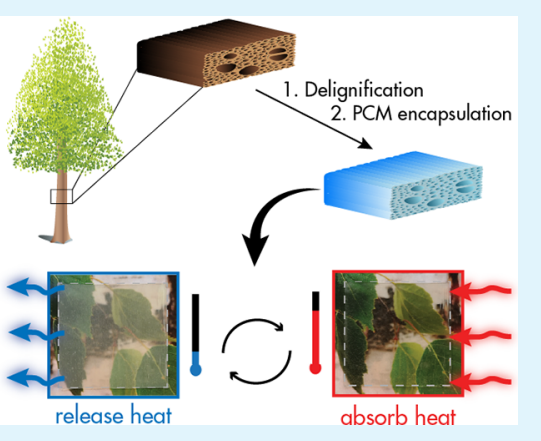
properties. This makes TW-TES composites interesting candidates for applications in energy-saving buildings.

KEYWORDS: wood, encapsulation, phase-change material, energy storage, biocomposite

\section{INTRODUCTION}

The global energy consumption in the building sector exceeds $30 \%$, and technologies for reduced energy consumption and $\mathrm{CO}_{2}$ emission are therefore under development. ${ }^{1}$ Transparent wood (TW) composites are of interest in energy-saving buildings because of low thermal conductivity $\left(0.15 \mathrm{~W} \mathrm{~m}^{-1}\right.$ $\left.\mathrm{K}^{-1}\right)$, ${ }^{2,3}$ high optical transmittance (92\% for $1.5 \mathrm{~mm}$ thick), ${ }^{4}$ and haze ( $80 \%$ for $1 \mathrm{~mm}$ thick), ${ }^{5}$ as well as favorable mechanical properties. $^{6-8}$ To prepare TW, a wood template is first chemically treated for removing lignin, which is the major light-absorbing component in wood. In a second step, light scattering is reduced by infiltrating the pore space with a polymer component matching the wood refractive index. ${ }^{9}$ In comparison to glass, which is generally used for lighttransmitting building structures, the TW shows better thermal insulation and could reduce heat loss. Furthermore, the TW exhibits a combination of high optical transmittance and haze, which offers uniform indoor lighting while preserving privacy. Most of the reported studies on TW for energy-saving applications focus on the excellent thermal insulating properties of this material. ${ }^{2,10}$ Thermal energy storage (TES) has emerged as a key technology to harvest and store solar energy. Latent heat storage systems based on phase-change materials (PCMs) are among the most efficient in reducing energy consumption because of their large latent heat capacity over a narrow temperature range. ${ }^{11-13}$ PCMs act as temperature regulators that can store and release thermal energy in order to shift the heating and cooling loads over time and thus reduce heat energy loss. In particular, organic PCMs store latent heat energy during a reversible solid-liquid phase-change process that occurs at the melting temperature of the material. ${ }^{14,15}$

The present study focuses on the incorporation of polyethylene glycol (PEG) in the TW. PEG is nontoxic and biodegradable, with a large latent heat and a tunable solidliquid transition temperature that can be varied by tuning PEG molecular weight. ${ }^{16,17}$ However, solid-liquid PCMs such as PEG suffer from leakage issues during melting, which limits their long-term thermal reliability. In order to address leakage issues, PEG can be entrapped by a surrounding polymer matrix, such as polymethyl methacrylate (PMMA). ${ }^{8-21}$ Porous supporting materials can be used to encapsulate the $\mathrm{PCM}^{22}$ such as silica and cellulosic networks. ${ }^{23,24}$ Here, wood is investigated as a PCM substrate. Wood is an abundant and renewable material, which has a unique hierarchical structure with organized cells formed during tree growth ${ }^{25-27}$ Wood cells have structurally advantageous microscale pores for chemical modification and polymer impregnation. The diameter could be $10-50 \mu \mathrm{m}$, with length at the scale of millimeters. Because delignified wood (DW) has a unique mesoporous cell wall structure, a high specific area, and a high adsorption capacity, ${ }^{6}$ it is an attractive supporting material for PCM encapsulation. Therefore, in this study, the PCM was encapsulated into a DW scaffold. Very few studies report the use of wood scaffold as a porous supporting material for

Received: March 28, 2019

Accepted: May 7, 2019

Published: May 7, 2019 
PCM. ${ }^{28-30}$ Excellent TES properties are reported in the present study, associated with high optical transmittance and haze. A multifunctional TW material was prepared via a twostep procedure, which involves wood delignification followed by encapsulation of the PEG/PMMA polymer blend into the porous DW scaffold. A schematic representation of the preparation procedure of the multifunctional TW, labeled as a transparent wood for thermal energy storage (TW-TES), is shown in Figure 1. TW-TES can store thermal energy even for

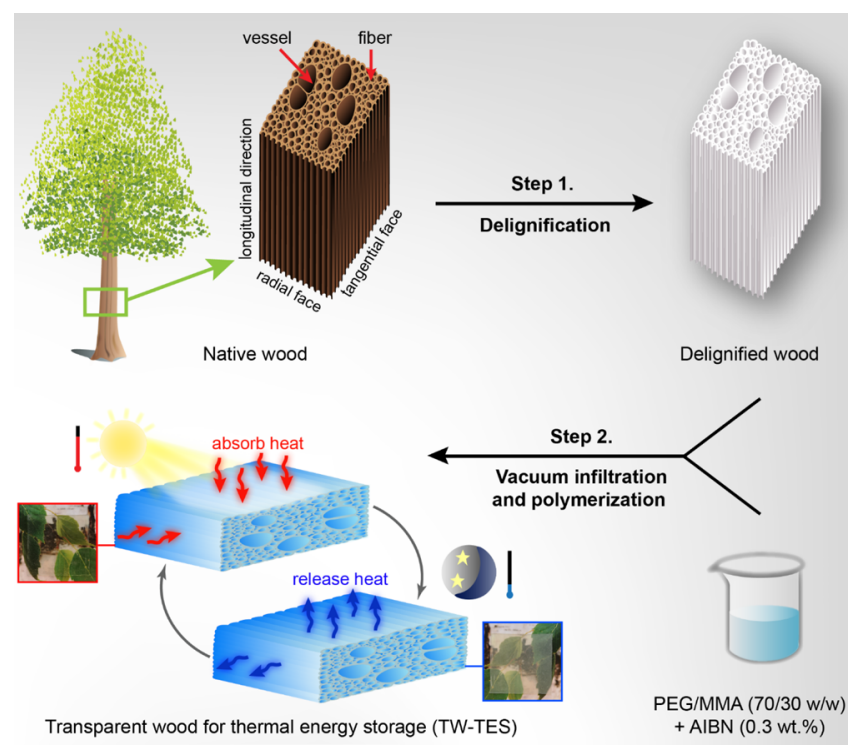

Figure 1. Schematic representation of the two-step preparation of TW-TES applications. First, wood is delignified to remove absorbing lignin, and subsequently, the PEG/MMA blend is infiltrated and polymerized into the wood fibers and vessels.

small temperature variations and combines excellent latent heat storage properties with low thermal conductivity, tunable optical transmittance, and robust mechanical performance. These properties make the multifunctional TW-TES composite a potential candidate for heat-transfer control in building applications, such as light-transmitting structures with reduced heat energy consumption and improved thermal comfort indoors. The objectives are to investigate the TW-TES concept and its potential. Also, the mesoscale structures are investigated so that the role of PCM distribution in TW-TES can be assessed.

\section{EXPERIMENTAL SECTION}

Materials. Silver birch wood (Betula pendula, purchased from Glimakra of Sweden $\mathrm{AB}$ ) with an oven-dried density of $620 \mathrm{~kg} / \mathrm{m}^{3}$ was used as a raw material. Specimens with dimensions of $2 \mathrm{~cm} \times 2$ $\mathrm{cm} \times 0.5 \mathrm{~mm}$ and $2 \mathrm{~cm} \times 2 \mathrm{~cm} \times 1.5 \mathrm{~mm}$ were prepared. More specimens were prepared for mechanical testing with dimensions of 5 $\mathrm{mm} \times 60 \mathrm{~mm} \times 1.5 \mathrm{~mm}$. Sodium chlorite $\left(\mathrm{NaClO}_{2}\right.$, Alfa Aesar), 2,2'azobis(2-methylpropionitrile) (AIBN, Sigma-Aldrich), and PEG (Sigma-Aldrich) with a molecular weight of $1000 \mathrm{~g} \mathrm{~mol}^{-1}$ were used as received. Methyl methacrylate (MMA, Sigma-Aldrich) was passed through a column of neutral aluminum oxide (Sigma-Aldrich) prior to use to remove the inhibitor.

Delignification of the Wood Samples. The delignification process was performed using $\mathrm{NaClO}_{2}(1 \mathrm{wt} \%)$ in an acetate buffer solution ( $\mathrm{pH} 4.6)$ at $80{ }^{\circ} \mathrm{C}$. The reaction was ended once the wood samples became white. The DW samples were then thoroughly washed several times with deionized water and sequentially dehydrated with ethanol and acetone.
Preparation of TW-TES Composites. PEG 1000 was heated at $45{ }^{\circ} \mathrm{C}$ until complete dissolution. MMA (30 wt \%) was added to the molten PEG $(70 \mathrm{wt} \%)$ solution and kept under stirring at $45{ }^{\circ} \mathrm{C}$ for $10 \mathrm{~min}$. The initiator, AINB (0.3 wt \% based on MMA), was then added to the PEG/MMA solution, and the blend was continuously stirred at $45{ }^{\circ} \mathrm{C}$ for $10 \mathrm{~min}$. The maximum PEG/PMMA ratio without any leakage during phase transition was $70 / 30(\mathrm{w} / \mathrm{w})$. The DW sample was then immersed in the blend solution for infiltration. Infiltration was performed under vacuum at room temperature for about $15 \mathrm{~min}$; it was repeated three times. The blend solution containing the DW samples was heated at $40{ }^{\circ} \mathrm{C}$ for a few minutes between each infiltration to delay PEG crystallization. The infiltrated DW template was finally sandwiched between two glass slides, packaged with aluminum foil, and polymerized in an oven at $70{ }^{\circ} \mathrm{C}$ for $4 \mathrm{~h}$. The final TW-TES composites prepared have thicknesses of 0.5 and $1.5 \mathrm{~mm}$ and possess a thin layer of PEG/PMMA at their surfaces. The density of the final composite was determined by measuring their dimensions and weight. The DW volume fraction was determined and is presented in Table S1.

Characterization. The cross-sectional morphologies of TW-TES composites were characterized by field emission scanning electron microscopy (Hitachi SEM S-4800, Japan). A differential scanning calorimeter (Mettler Toledo DSC1, Switzerland) was used to analyze the thermal properties of neat PEG, PEG/PMMA polymer blend, and TW-TES composite under nitrogen with a flow rate of $50 \mathrm{~mL} \mathrm{~min}{ }^{-1}$. The samples were heated from 0 to $60^{\circ} \mathrm{C}$ with a heating rate of $2{ }^{\circ} \mathrm{C}$ $\mathrm{min}^{-1}$. The latent heat was determined by numerical integration of the area of the thermal transition peak. The thermal reliability of the TWTES composite was investigated by performing 20 heating-cooling cycles. The data were recorded from the second scan. The thermal stability of the TW-TES composite was studied by thermogravimetric analysis (TGA) using a Mettler Toledo TGA/DSC1 (Switzerland) with a heating rate of $10{ }^{\circ} \mathrm{C} \mathrm{min}{ }^{-1}$ from room temperature to $600{ }^{\circ} \mathrm{C}$ under nitrogen atmosphere. A light flash apparatus (LFA 467 HyperFlash Netzsch, Germany) was employed to determine crossplane thermal diffusivities $(\alpha)$ on square samples $(20 \times 20 \times 1.5$ $\mathrm{mm})$. The measurements were performed at $45^{\circ} \mathrm{C}$ in order to avoid the PCM phase transition. The sample surfaces were graphitized using a graphite spray before the measurements. Thermal conductivity, $\kappa$, was then calculated from the equation $\kappa=\rho \alpha C_{p}$, where $\rho$ is the density and $C_{p}$ is the specific heat capacity of the material. The chemical structure of native wood (NW), DW, neat PEG, neat PMMA, and TW-TES composite was evaluated by Fourier transform infrared spectrometry (FTIR) using a PerkinElmer spectrum 100 FTIR equipped with a MKII Golden Gate, single-reflection accessory unit with a diamond ATR crystal (Graseby Specac Ltd., UK). The spectra were recorded at room temperature in the range of 4000-600 $\mathrm{cm}^{-1}$. Tensile tests and three-point bending tests were performed using an Instron 5944 (USA) instrument equipped with a $500 \mathrm{~N}$ load cell. The tests were carried out with a $10 \% \mathrm{~min}^{-1}$ strain rate and span of $30 \mathrm{~mm}$. All samples were preconditioned for $24 \mathrm{~h}$ and tested in a room at a temperature of $22 \pm 1{ }^{\circ} \mathrm{C}$ and $50 \pm 2 \%$ relative humidity. The optical measurements were performed using an integrating sphere in the visible and NIR wavelength region $(400-1000 \mathrm{~nm})$. A Quartz tungsten halogen light source (model 66181 from Oriel Instruments) with strong, stable output mainly in the visible and NIR region was used. The visible transmittance and haze were measured according to ASTM D1003 "Standard Method for Haze and Luminous Transmittance of Transparent Plastics"31 by placing the sample at the entrance port of the integrating sphere and following the same procedure as previously reported in another study. ${ }^{6}$ Thermal images were captured using an infrared camera (FLIR A655sc).

\section{RESULTS AND DISCUSSION}

Morphological and Chemical Analysis. A TW composite is prepared with encapsulated PCM for TES applications. Silver birch was used as a starting material. Wood tissues comprise elongated tubular cells preferably aligned in the longitudinal direction of the stem. In silver birch species, close- 


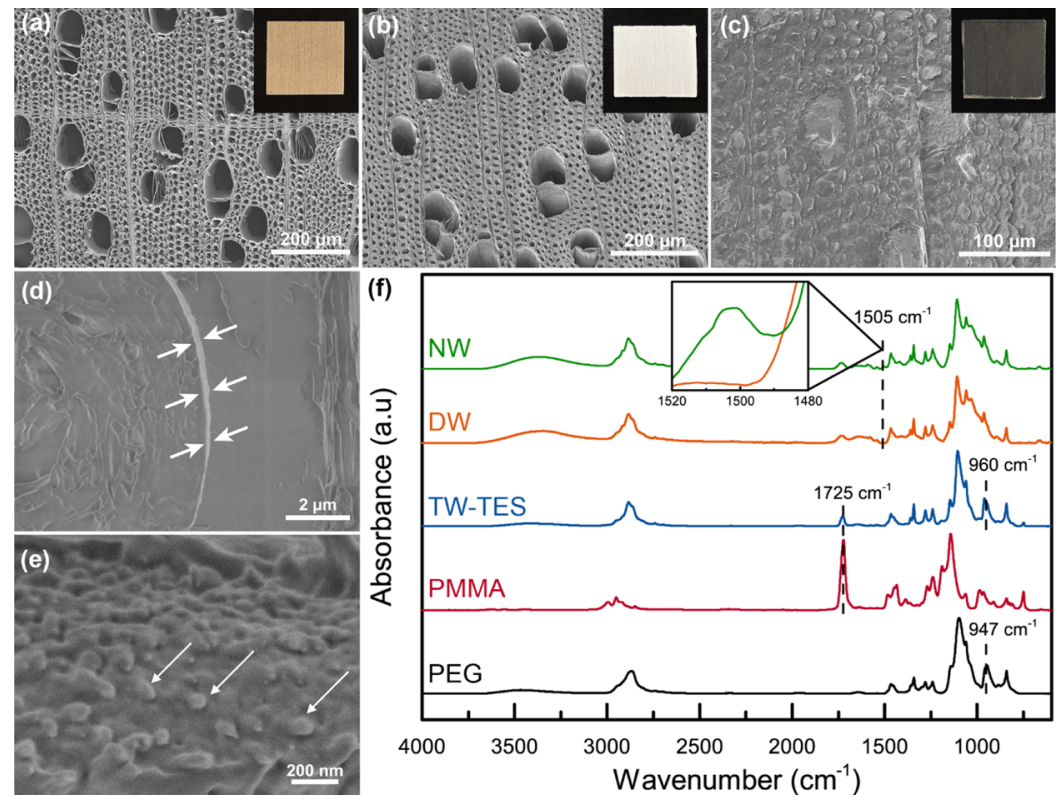

Figure 2. SEM micrographs showing (a) original birch wood and (b) delignified birch wood. SEM images of TW-TES (c) shows the successful impregnation of DW with PEG/PMMA and (d) shows the integrity between wood cell wall and PEG/PMMA matrix. (e) SEM micrograph of the interior of TW-TES wood cell wall. (f) FTIR spectra of NW, DW, TW-TES, neat PMMA, and neat PEG.

ended libriform fibers provide mechanical support, whereas water conduction is supplied by open-ended vessels. Birch fibers and vessels have a mean diameter of 18 and $82 \mu \mathrm{m}$, respectively. At the ultrastructural level, the cell wall structure of the wood cells consists of layers with oriented cellulose microfibrils bonded by a mixed hemicelluloses-lignin matrix. Figure 2a shows the SEM image of the cell wall structure of birch wood. The delignification process adds nanoscale porosity in the middle lamella (lignin-rich region) and in the cell wall, ${ }^{6}$ while preserving the anisotropic structure of wood (Figures 2b and S1). PEG with a molecular weight of $1000 \mathrm{~g}$ $\mathrm{mol}^{-1}$ was chosen as the PCM owing to its excellent energy storage capacity at a suitable working temperature range; in addition, PEG is highly miscible with wood. ${ }^{32-34}$ In order to guarantee high-energy density and avoid PEG leakage during the phase transition, PEG (70 wt \%) was mixed with MMA monomer (30 wt \%) and AIBN as an initiator, the blend was infiltrated in the DW scaffold, and then MMA polymerized, so that a polymer blend termed PEG/PMMA was formed. The DW scaffold is used as a supporting structure for encapsulation of the PEG/PMMA polymer blend. TW-TES composites with thicknesses of 0.5 and $1.5 \mathrm{~mm}$ were prepared. The morphology of the TW-TES composite was investigated using SEM and is presented in Figure 2c. Upon infiltration, the wood microstructure is preserved and the PEG/PMMA blend is homogeneously distributed at the scale of $20 \mu \mathrm{m}$ so that the cell lumen is completely filled by the polymer phase. PEG/ PMMA is of immiscible two-phase polymer blend. ${ }^{19,20}$ No interface gaps were apparent between PEG/PMMA and the wood cell wall. This indicates favorable interfacial interaction between PEG/PMMA polymer blend and the wood cell wall (Figure 2d). This may be attributed to the good miscibility between the hydrophilic PEG phase and the wood cell wall. Figure 2e shows the interior of TW-TES wood cell wall where polymer domains are apparent, indicating the successful impregnation of the wood cells.

In order to assess if the PEG phase is located in the cell wall, a DW piece was soaked in a 30 wt \% PEG 1000 aqueous solution and the cell wall morphology was evaluated. Figure S2 shows a high-resolution SEM image of the wood cell wall after PEG infiltration. After PEG infiltration, PEG-rich domains could be identified and no pores were detected at this scale in contrast with DW before infiltration (Figure S1). The similarities between the SEM micrographs of the cell wall interior shown in Figures 2e and S2 provide support for PEG diffusion into the wood cell wall. Figure $2 \mathrm{e}$ indicates that the PEG-rich domain inside the cell wall is at the scale of 100-200 nm particles.

The chemical interactions between the PCM and the DW template in TW-TES composites were analyzed by the FTIR analysis. FTIR spectra of NW, DW, neat PMMA, neat PEG, and TW-TES composite are presented (Figure 2f). In comparison with $\mathrm{NW}$, the peak at $1505 \mathrm{~cm}^{-1}$ attributed to aromatic skeleton vibrations from lignin is lacking from the DW spectrum. ${ }^{35}$ This confirms successful removal of lignin by delignification. In addition, all of the major characteristic absorption peaks of DW, PEG, and PMMA are present in the TW-TES composite. The absorption peak of PMMA ascribed to $\mathrm{C}=\mathrm{O}$ stretching $\left(1725 \mathrm{~cm}^{-1}\right)$ is present. Moreover, shift in the $\mathrm{O}-\mathrm{H}$ stretching vibration peak in the TW-TES (3419 $\left.\mathrm{cm}^{-1}\right)$ spectrum compared with that of DW $\left(3350 \mathrm{~cm}^{-1}\right)$ and PEG $\left(3468 \mathrm{~cm}^{-1}\right)$ indicates hydrogen-bonding interactions between PEG and DW. The PEG absorption peak at $947 \mathrm{~cm}^{-1}$, attributed to $-\mathrm{CH}_{2}$ vibrations, ${ }^{36}$ is shifted in TW-TES, also suggesting intermolecular interaction between PEG and DW. Thus, the DW template can effectively prevent leakage because of capillary forces and intermolecular interactions with the small-scale PCM domains. No new absorption peak is apparent in the TW-TES spectrum, so that only intermolecular interactions are expected between PEG and PMMA and between PEG and the DW template. The stabilization of PEG in PMMA and DW template does not significantly alter the chemical structure of PEG, and the thermal properties of PEG are possibly preserved.

Thermal Properties. The TES properties are important for the application of TW-TES in energy-saving buildings. 

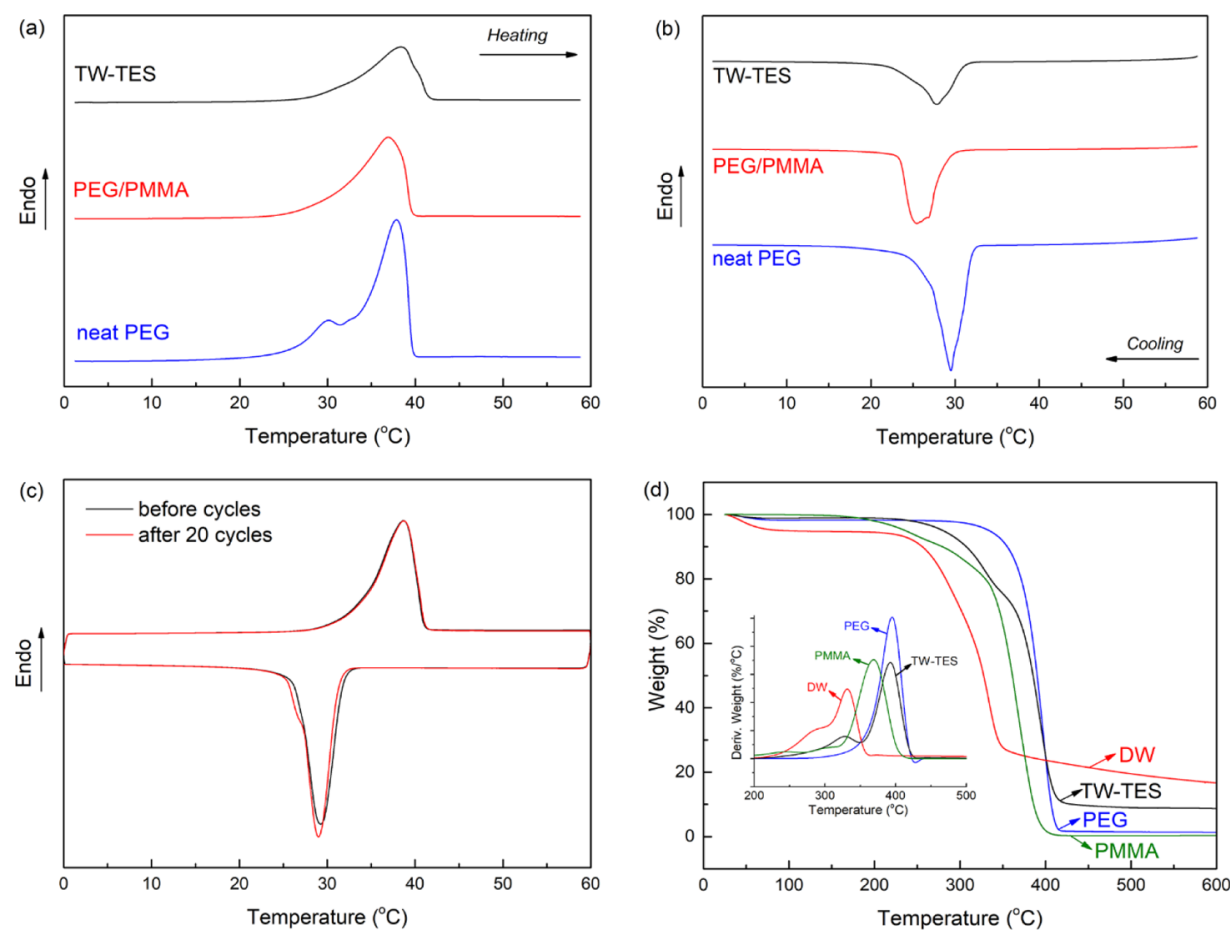

Figure 3. (a) DSC scans of neat PEG, PEG/PMMA blend, and TW-TES obtained while heating from 0 to $60{ }^{\circ} \mathrm{C}$ followed by (b) cooling process. (c) DSC curves of TW-TES before and after thermal cycling, indicating good thermal reliability after 20 cycles. (d) TG/DTG curves of DW, neat PEG, neat PMMA and TW-TES.

Table 1. Thermal Properties of Neat PEG, Neat PEG/PMMA Blend, and TW-TES Composite During the Melting and Crystallization Processes

$\begin{array}{lcccccc} & T_{\mathrm{m}}\left[{ }^{\circ} \mathrm{C}\right]^{a} & \Delta H_{\mathrm{m}}\left[\mathrm{J} \mathrm{g}^{-1}\right]^{b} & \Delta H_{\mathrm{m}}^{\mathrm{Th}}\left[\mathrm{J} \mathrm{g}^{-1}\right]^{c} & T_{\mathrm{c}}\left[{ }^{\circ} \mathrm{C}\right]^{d} & \Delta H_{\mathrm{c}}\left[\mathrm{J} \mathrm{g}^{-1}\right]^{e} & \Delta H_{\mathrm{c}}^{\mathrm{Th}}\left[\mathrm{J} \mathrm{g} \mathrm{g}^{-1}\right]^{f} \\ \text { neat PEG } & 37.8 \pm 0.3 & 159.0 \pm 2.1 & & 29.5 \pm 0.7 & 161.5 \pm 2.5 & \\ \text { PEG/PMMA (70/30 w/w) } & 36.9 \pm 0.2 & 103.0 \pm 2.5 & 111.3 & 25.5 \pm 1.2 & 101.1 \pm 0.2 & 113.1 \\ \text { TW-TES composite } & 38.3 \pm 0.3 & 76.3 \pm 3.4 & 77.3 & 28.6 \pm 1.3 & 74.2 \pm 3.1 & 78.5\end{array}$

${ }^{a}$ Melting temperature. ${ }^{b}$ Latent heat of melting. ${ }^{c}$ Theoretical latent heat of melting. ${ }^{d}$ Crystallization temperature. ${ }^{e}$ Latent heat of crystallization.

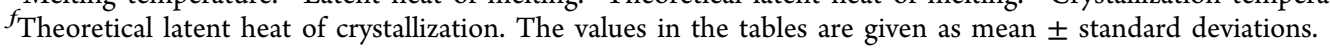

Thermal storage cycles include two steps: absorption of latent heat by the crystalline polymer (PEG) upon heating above the melting temperature $\left(T_{\mathrm{m}}\right)$ and latent heat release during cooling until the crystallization temperature $\left(T_{c}\right)$. The melting and cooling curves of neat PEG, PEG/PMMA blend, and TWTES composite are presented in Figure 3a,b, respectively. TWTES shows excellent thermal properties with latent heat of melting and crystallization of about 76 and $74 \mathrm{~J} \mathrm{~g}^{-1}$, respectively. The melting process of TW-TES occurs over a temperature range between $\sim 27$ and $\sim 40{ }^{\circ} \mathrm{C}$, with a $T_{\mathrm{m}}$ of 38 ${ }^{\circ} \mathrm{C}$. When heated above $T_{\mathrm{m}}$, the TW-TES composite consists of molten PEG encapsulated into the wood template and surrounded by PMMA. At this stage, the TW-TES stores latent heat of the liquid PCM. Cooling until the crystallization point $\left(T_{\mathrm{c}}=29^{\circ} \mathrm{C}\right)$ will initiate the crystallization of PEG and hence release the stored latent heat. The differential scanning calorimetry (DSC) curves show that TW-TES exhibits endothermic and exothermic behavior similar to the PEG/ PMMA blend. Neat PEG exhibits a shoulder on the leading edge of the endothermic peak associated with the melting point of crystallites. The presence of a shoulder is a consequence of heterogeneous melting and is attributed to variations in crystal thicknesses. ${ }^{17,37}$ Further support is given in Table 1, which summarizes the latent heat of melting $\left(\Delta H_{\mathrm{m}}\right)$ and crystallization $\left(\Delta H_{c}\right)$ and characteristic temperatures $\left(T_{\mathrm{m}}\right.$ and $T_{c}$ ) of neat PEG, PEG/PMMA, and TW-TES composite. The theoretical data were defined as follow: $\Delta H^{\mathrm{Th}}=X \cdot \Delta H^{\mathrm{PEG}}$, where $\Delta H^{\mathrm{Th}}$ is the theoretical latent heat, $\Delta H^{\mathrm{PEG}}$ is the latent heat of neat PEG, and $X$ is the mass fraction of PEG. The enthalpy values of PEG/PMMA blend and TW-TES composite are proportional to the PEG fraction and are shown in Table 1. The experimental results for TW-TES were close to predicted data based on PEG/PMMA behavior. This can be attributed to the preserved thermal performance of PEG in TW-TES, and it indicates that the domain size of PEG is sufficiently large so that PEG preserves its melting and crystallization behavior. If PEG was completely soluble in the wood cell wall, the melting and crystallization behavior could have been altered in a negative manner because of the lower PEG crystallinity.

The phase-change phenomenon is critical to TW-TES performance, and it was therefore investigated if PEG could crystallize in the wood cell wall. A DW template was soaked in 30 wt \% aqueous PEG solution in order to selectively infiltrate the wood cell walls, while keeping the lumen pore space free of polymer. The DSC analysis was performed on the DW template with PEG infiltrated cell walls (Figure S3). Latent heat of melting and crystallization of, respectively, 39 and $38 \mathrm{~J}$ 

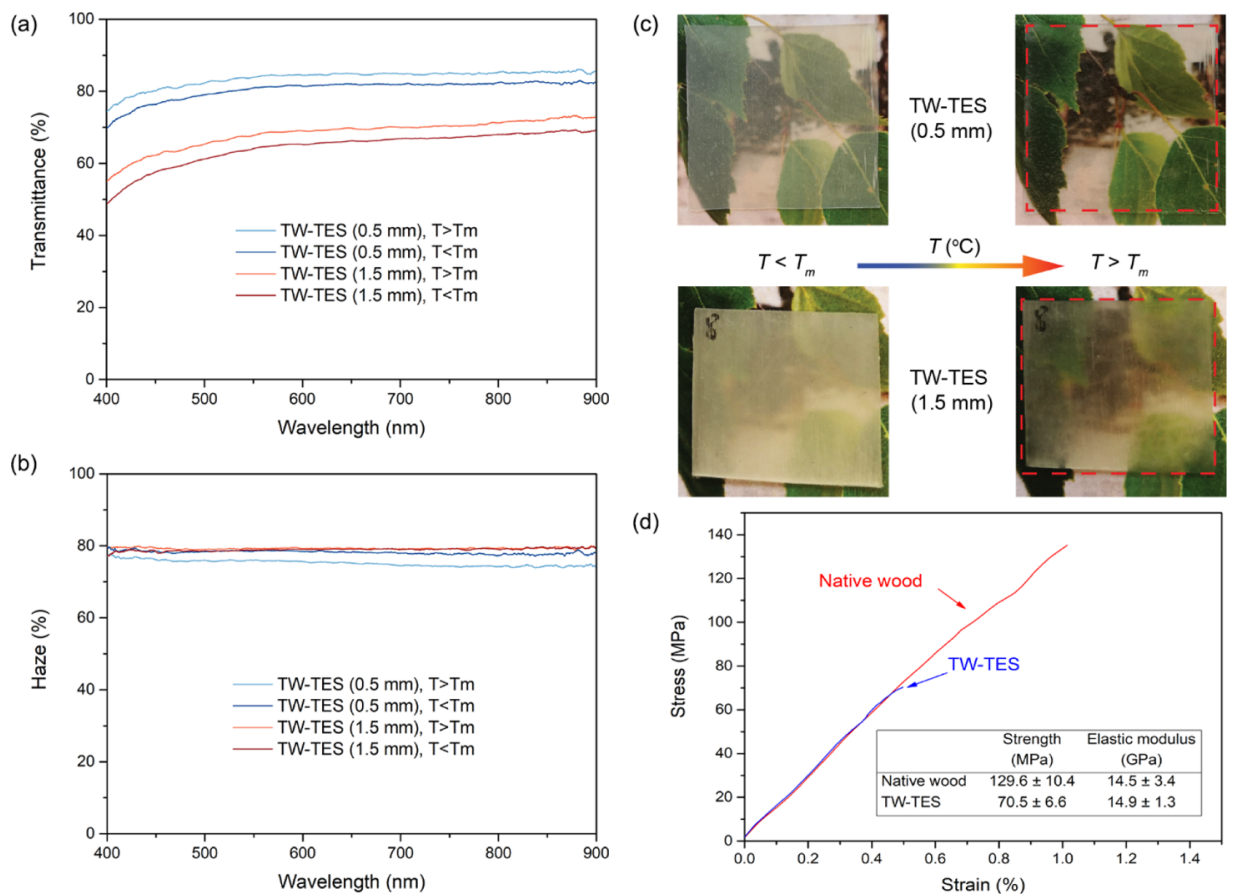

Figure 4. Optical (a) transmittance and (b) haze of TW-TES at below and above the melting temperature $\left(T_{\mathrm{m}}\right)$ of PCM in the visible spectrum range. (c) Images showing the visible change from opaque to transparent with increase in temperature for 0.5 and $1.5 \mathrm{~mm}$ thick TW-TES specimens. The transmittance is tunable by varying the temperature. (d) Tensile test curves and table showing the strength and elastic modulus of NW and TW-TES. Note: the values in the tables are given as mean \pm standard deviations.

$\mathrm{g}^{-1}$ were achieved when PEG was located in the wood cell wall only. It is concluded that crystallization of PEG does not only take place in the microscale lumen space but also in the wood cell wall. This provides further information with respect to PEG distribution and supports that the wood cell wall contains PEG-rich domains. The PCM penetrates throughout the whole wood template, ensuring high heat storage efficiency in TWTES.

The thermal reliability of the TW-TES composite was evaluated by performing 20 heating-cooling cycles. Data are presented in Figure 3c. After 20 cycles, the phase-change temperatures, $T_{\mathrm{m}}$ and $T_{\mathrm{c}}$, remain comparable with those at the initial state. After cycling, the latent heat of crystallization $\Delta H_{c}$ showed a minor increase of $0.55 \%$ because of enhanced nucleation of PEG crystallites after several heating-cooling cycles. The latent heat of melting, $\Delta H_{\mathrm{m}}$, did not show any variations. TW-TES exhibits excellent thermal reliability after 20 thermal cycles.

The thermal stability was evaluated using TGA in nitrogen, and the TG curves of neat PEG and TW-TES are shown in Figure $3 \mathrm{~d}$. From 30 to $150{ }^{\circ} \mathrm{C}$, TW-TES exhibits only $1.0 \%$ weight loss attributed to residual moisture evaporation, which is much lower than that for the DW template (5.3\%). TW-TES exhibits a two-step degradation starting from $\sim 290{ }^{\circ} \mathrm{C}$, including the degradation of DW template and the degradation of PMMA and PEG compounds. The thermo-oxidative stability was also studied in oxygen (Figure S4). Under these conditions, thermal oxidation of TW-TES starts from $\sim 190$ ${ }^{\circ} \mathrm{C}$. The degradation of TW-TES is initiated by the production of formic esters originating from the degradation of PEG. ${ }^{38}$ Overall, these results show that TW-TES is thermally stable below $\sim 290{ }^{\circ} \mathrm{C}$ in the absence of oxygen (nitrogen environment), and below $\sim 190{ }^{\circ} \mathrm{C}$ in an oxidative environment (oxygen).
Thermal insulating materials are essential in limiting heat loss and thus reducing energy consumption in buildings. A light flash test was employed in order to preliminary evaluate the thermal conductivity of TW-TES composites. TW-TES has efficient thermal insulation properties with a low cross-plane thermal conductivity of $0.30 \mathrm{~W} \mathrm{~m}^{-1} \mathrm{~K}^{-1}$, compared with 1.36 $\mathrm{W} \mathrm{m} \mathrm{m}^{-1} \mathrm{~K}^{-1}$ for normal glass (Table S2). The combination of heat storage and thermal insulation properties is favorable.

Optical Function and Mechanical Properties. Wood optical transparency is obtained by first partially removing the lignin component and then introducing a material matching closely the wood refractive index in order to reduce the light scattering sources located at the air/wood interfaces in the lumen area and inside the cell wall. ${ }^{38}$ In our study, optical transmittance was obtained by infiltrating the PEG/PMMA blend in the porous DW structure.

TW-TES shows good optical properties with switchable optical transmittance during the phase-change process. The optical properties of TW-TES were determined using an integrating sphere at temperatures below and above $T_{\mathrm{m}}$ to assess the variations in optical properties with temperature (Figure 4a,b). The optical transmittance of TW-TES increases by $6 \%$ at $\lambda=550 \mathrm{~nm}$ after the phase change $\left(T>T_{\mathrm{m}}\right)$ as PEG crystals melt in the composite. As the temperature is lowered below $T_{\mathrm{m}}$, the optical transmittance of TW-TES is reduced because of the crystallization of PEG. The change in transmittance can be visually observed as the TW-TES composite changes from opaque to transparent when undergoing the phase transitions (Figure $4 \mathrm{c}$ ). Above $T_{\mathrm{m}}, 1.5 \mathrm{~mm}$ thick TW-TES shows a transmittance of $68 \%$. Lower thickness results in higher optical transmittance because a shorter light pathway lowers light attenuation. ${ }^{39}$ The TW-TES specimen with a thickness of $0.5 \mathrm{~mm}$ results in transmittance up to $84 \%$ above $T_{\mathrm{m}}$. It should be noted that the PEG/PMMA blend has 

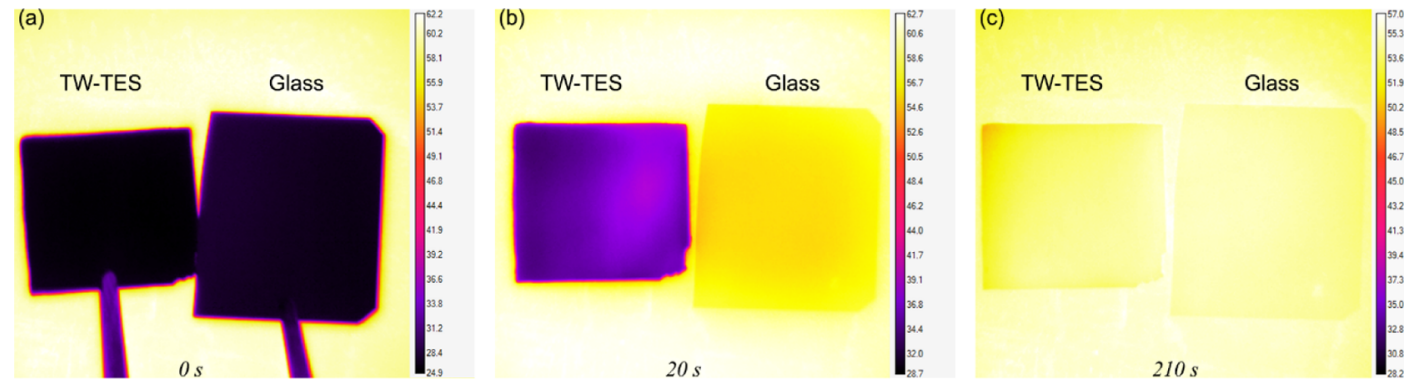

Figure 5. Thermal images for thermal evolution of TW-TES and glass with respect to time when placed from room temperature to a surface heated at $60{ }^{\circ} \mathrm{C}$. (a) Start of the experiment, (b) after $20 \mathrm{~s}$, the glass specimen has reached the temperature of the heated surface and (c) TW-TES reaches it after $210 \mathrm{~s}$.

a transmittance of $86 \%$ above $T_{\mathrm{m}}$. The difference in transmittance is probably caused by the refractive index mismatch between holocellulose (1.53), PEG (1.46), and PMMA (1.49). ${ }^{38,40}$ Haze is the percentage of transmitted light that is scattered at large angles from the direction of light propagation. ${ }^{41}$ The haze of $1.5 \mathrm{~mm}$ thick TW-TES $(77 \%$ at $\lambda=$ $550 \mathrm{~nm}$ ) did not significantly vary with temperature. As the haze was measured by subtracting the transmitted light at small scattering angles, the visual difference might be due to transmitted light which is scattered to larger angles. A relative decrease in haze of $3 \%$ was observed for the thinner specimens when heated above $T_{\mathrm{m}}$. This can be attributed to a reduction in scattering centers, such as voids, upon melting of PEG crystals. The visual change in transparency of TW-TES with increased temperature can be advantageous for applications such as temperature sensors for the environment and light-transmitting structures with homogeneous lighting.

The mechanical properties were evaluated below $T_{\mathrm{m}}$ using three-point bending and tensile tests. The reduced stressstrain curves of TW-TES from flexural tests for longitudinal properties are shown in Figure S5. TW-TES shows a flexural strength of $74.5 \pm 10.2 \mathrm{MPa}$ and a strain to failure as high as $3.2 \pm 0.6 \%$. Glass shows brittle nature with a low strain to failure $(0.2 \pm 0.1 \%)$, whereas TW-TES is much more ductile (3.2\%). Overall, the work to fracture of TW-TES $\left(1.9 \mathrm{MJ} \mathrm{m}^{-3}\right.$, area under stress-strain curve) is about 10 times higher than that for glass $\left(0.2 \mathrm{MJ} \mathrm{m}^{-3}\right)$ because of more favorable mechanisms of failure in TW-TES composites. Tensile test results for NW and TW-TES are shown in Figure 4d. TW-TES shows high elastic modulus $(14.9 \pm 1.3 \mathrm{GPa})$ compared with polymers, and this is similar to NW $(14.5 \pm 3.4 \mathrm{GPa})$. TWTES shows a strength of $70.5 \pm 6.6 \mathrm{MPa}$, which is lower than that for NW $(129.6 \pm 10.4 \mathrm{MPa})$. The lower strength of the TW-TES composite could be attributed to the presence of residual nanoporosity in the cell wall because of delignification. In addition, PEG impregnation reduces mechanical strength because molar mass and PEG glass-transition temperature are low, so that stress transfer between cellulose fibrils in the cell wall is compromised. ${ }^{33}$ In general, TW-TES shows satisfactory mechanical strength and modulus for load-bearing applications. An important reason is the relatively low porosity of birch wood, which means that the content of wood cell wall material is high.

In order to demonstrate the TES performance of TW-TES in real applications, an infrared camera was used to record temperature changes in TW-TES during heating. Specimens at room temperature were placed on a heating plate set at a temperature of $60{ }^{\circ} \mathrm{C}$, and the time for each specimen to reach the heating plate temperature was recorded. Figure 5 shows thermal images of TW-TES and glass specimens when placed in contact with a surface heated at $60{ }^{\circ} \mathrm{C}$. The samples were transferred simultaneously from room temperature to the heated surface (Figure 5a). After $20 \mathrm{~s}$, the glass specimen reached the temperature of the heated surface (Figure 5b), indicating the fast temperature equilibration. In contrast, TWTES required $210 \mathrm{~s}$ of heating in order to reach the equilibrium temperature (Figure $5 \mathrm{c}$ ), showing the heat storage capacity and thermal energy regulating property of TW-TES. The equilibration temperature of TW-TES was compared with TW without PCM, prepared as previously reported. ${ }^{6}$ The results are shown in the Supporting Information (Video S1). The results show that temperature equilibrium of the specimens is first reached by glass, followed closely by TW without PCM, and finally by TW-TES. Compared with TW without PCM, TW-TES shows great efficiency in terms of TES. These differences between glass and TW-TES are attributed to the lower thermal conductivity of TW-TES and to the ability of the TW-TES composite to absorb and store thermal energy. TW-TES is a candidate as heat-storage and light-transmitting material for applications in energy-saving buildings.

\section{CONCLUSIONS}

This study presents a novel concept of multifunctional TWTES that combines mechanical properties, TES, and optical transmittance. A mesoporous DW template was used as a supporting, nonleaking substrate material for encapsulation of the PCM. The TW-TES composite was obtained by impregnation with a liquid PEG/MMA blend, followed by MMA polymerization. The final impregnated polymer component was a $70 / 30(\mathrm{w} / \mathrm{w})$ physical blend of PEG/ PMMA.

The TES properties of the TW-TES composite were highly favorable and proportional to the $49 \mathrm{wt} \%$ PEG content. The TES function was combined with high mechanical properties. In addition, the materials showed tunable optical transmittance when the external temperature was increased because the PEG phase was melting. With increasing thickness, the optical transmittance is reduced because of increasing light attenuation. This can be a limitation for applications of higher thickness TW-TES as light-transmitting materials. The optical transmittance of TW-TES can be enhanced by reducing the wood volume fraction by using higher porosity wood species, so that the number of wood/polymer interfaces is lowered.

Dissolution experiments suggest that the PEG phase was continuous in the wood lumen pore space. The morphological 
analysis of TW-TES composites also indicates that a PEG-rich phase was present in the wood cell wall, in the form of 100$200 \mathrm{~nm}$ mesoscale domains. The PEG distribution is critical to the mechanical, optical, and TES properties of the material.

The design of TW-TES materials requires optimization of mechanical properties with respect to TES capacity. The PEG content could be increased by the selection of higher porosity wood species, but then the mechanical performance would be reduced.

The thermal properties of the TW-TES composite can be further tailored, for instance, by tuning the melting temperature of PEG. The present concept of multifunctional TW materials can expand the applications of wood-based materials to new areas including temperature sensors, heat storage, and light-transmitting structural materials.

\section{ASSOCIATED CONTENT}

\section{S Supporting Information}

The Supporting Information is available free of charge on the ACS Publications website at DOI: 10.1021/acsami.9b05525.

SEM image of the interior of DW cell wall, SEM image of the interior of DW cell wall infiltrated with PEG; DSC curve of PEG infiltrated into DW cell wall; TGA of DW, PEG, PMMA, and TW-TES in oxygen; three-point bending stress-strain curves of glass and TW-TES; weight fraction and volume fraction in the TW-TES composite; and thermal conductivity of glass and TWTES (PDF)

Thermal evolution of TW-TES, TW without PCM, and glass specimens when placed from room temperature to a surface heated at $60{ }^{\circ} \mathrm{C}(\mathrm{MP} 4)$

\section{AUTHOR INFORMATION}

\section{Corresponding Author}

*E-mail: blund@kth.se.

\section{ORCID}

Céline Montanari: 0000-0001-6017-1774

Yuanyuan Li: 0000-0002-1591-5815

Lars A. Berglund: 0000-0001-5818-2378

\section{Notes}

The authors declare no competing financial interest.

\section{ACKNOWLEDGMENTS}

We acknowledge funding from KTH and European Research Council Advanced Grant (no. 742733) Wood NanoTech, and funding from Knut and Alice Wallenberg foundation through the Wallenberg Wood Science Center at KTH Royal Institute of Technology. Prof. A. Fina and Dr. F. Carosio, Dipartimento di Scienza Applicata e Tecnologia, Politecnico di Torino Alessandria, Italy, are acknowledged for the light-flash measurements. The authors also acknowledge the Umea Core Facility Electron Microscopy (UCEM) at the Chemical Biological Centre $(\mathrm{KBC})$, Umeå University, for the ultramicrotome sectioning of the DW substrate.

\section{REFERENCES}

(1) International Energy Agency. Transition to Sustainable Buildings, 2013.

(2) Li, T.; Zhu, M.; Yang, Z.; Song, J.; Dai, J.; Yao, Y.; Luo, W.; Pastel, G.; Yang, B.; Hu, L. Wood Composite as an Energy Efficient Building Material: Guided Sunlight Transmittance and Effective Thermal Insulation. Adv. Energy Mater. 2016, 6, 1601122.
(3) Li, Y.; Fu, Q.; Rojas, R.; Yan, M.; Lawoko, M.; Berglund, L. Lignin-Retaining Transparent Wood. ChemSusChem 2017, 10, 34453451.

(4) Li, Y.; Yang, X.; Fu, Q.; Rojas, R.; Yan, M.; Berglund, L. Towards Centimeter Thick Transparent Wood through Interface Manipulation. J. Mater. Chem. A 2018, 6, 1094-1101.

(5) Zhu, M.; Li, T.; Davis, C. S.; Yao, Y.; Dai, J.; Wang, Y.; AlQatari, F.; Gilman, J. W.; Hu, L. Transparent and Haze Wood Composites for Highly Efficient Broadband Light Management in Solar Cells. Nano Energy 2016, 26, 332-339.

(6) Li, Y.; Fu, Q.; Yu, S.; Yan, M.; Berglund, L. Optically Transparent Wood from a Nanoporous Cellulosic Template: Combining Functional and Structural Performance. Biomacromolecules 2016, 17, 1358-1364.

(7) Zhu, M.; Song, J.; Li, T.; Gong, A.; Wang, Y.; Dai, J.; Yao, Y.; Luo, W.; Henderson, D.; Hu, L. Highly Anisotropic, Highly Transparent Wood Composites. Adv. Mater. 2016, 28, 5181-5187.

(8) Fu, Q.; Yan, M.; Jungstedt, E.; Yang, X.; Li, Y.; Berglund, L. A. Transparent Plywood as a Load-Bearing and Luminescent Biocomposite. Compos. Sci. Technol. 2018, 164, 296-303.

(9) Li, Y.; Vasileva, E.; Sychugov, I.; Popov, S.; Berglund, L. Optically Transparent Wood: Recent Progress, Opportunities, and Challenges. Adv. Opt. Mater. 2018, 6, 1800059.

(10) Wang, X.; Zhan, T.; Liu, Y.; Shi, J.; Pan, B.; Zhang, Y.; Cai, L.; Shi, S. Q. Large-Size Transparent Wood for Energy-Saving Building Applications. ChemSusChem 2018, 11, 4086.

(11) Sharma, A.; Tyagi, V. V.; Chen, C. R.; Buddhi, D. Review on Thermal Energy Storage with Phase Change Materials and Applications. Renewable Sustainable Energy Rev. 2009, 13, 318-345.

(12) Akeiber, H.; Nejat, P.; Majid, M. Z. A.; Wahid, M. A.; Jomehzadeh, F.; Zeynali Famileh, I.; Calautit, J. K.; Hughes, B. R.; Zaki, S. A. A Review on Phase Change Material (PCM) for Sustainable Passive Cooling in Building Envelopes. Renewable Sustainable Energy Rev. 2016, 60, 1470-1497.

(13) Soares, N.; Costa, J. J.; Gaspar, A. R.; Santos, P. Review of passive PCM latent heat thermal energy storage systems towards buildings' energy efficiency. Energy Build. 2013, 59, 82-103.

(14) Pielichowska, K.; Pielichowski, K. Phase Change Materials for Thermal Energy Storage. Prog. Mater. Sci. 2014, 65, 67-123.

(15) Sarier, N.; Onder, E. Organic Phase Change Materials and Their Textile Applications: An Overview. Thermochim. Acta 2012, 540, 7-60.

(16) Ginés, J. M.; Arias, M. J.; Rabasco, A. M.; Novák, C.; RuizConde, A.; Sánchez-Soto, P. J. Thermal Characterization of Polyethylene Glycols Applied in the Pharmaceutical Technology Using Differential Scanning Calorimetry and Hot Stage Microscopy. J. Therm. Anal. 1996, 46, 291-304.

(17) Pielichowski, K.; Flejtuch, K. Differential Scanning Calorimetry Studies on Poly(Ethylene Glycol) with Different Molecular Weights for Thermal Energy Storage Materials. Polym. Adv. Technol. 2002, 13, 690-696.

(18) Alkan, C.; Sari, A.; Uzun, O. Poly(Ethylene Glycol)/Acrylic Polymer Blends for Latent Heat Thermal Energy Storage. AIChE J. 2006, 52, 3310-3314.

(19) Zhang, L.; Zhu, J.; Zhou, W.; Wang, J.; Wang, Y. Characterization of Polymethyl Methacrylate/Polyethylene Glycol/ Aluminum Nitride Composite as Form-Stable Phase Change Material Prepared by in Situ Polymerization Method. Thermochim. Acta 2011, $524,128-134$.

(20) Sarı, A.; Alkan, C.; Karaipekli, A.; Uzun, O. Poly(Ethylene Glycol)/Poly(Methyl Methacrylate) Blends as Novel Form-Stable Phase-Change Materials for Thermal Energy Storage. J. Appl. Polym. Sci. 2010, 116, 929-933.

(21) Kenisarin, M. M.; Kenisarina, K. M. Form-Stable Phase Change Materials for Thermal Energy Storage. Renewable Sustainable Energy Rev. 2012, 16, 1999-2040.

(22) Huang, X.; Chen, X.; Li, A.; Atinafu, D.; Gao, H.; Dong, W.; Wang, G. Shape-Stabilized Phase Change Materials Based on Porous 
Supports for Thermal Energy Storage Applications. Chem. Eng. J.

2019, 356, 641-661.

(23) Min, X.; Fang, M.; Huang, Z.; Liu, Y.; Huang, Y.; Wen, R.; Qian, T.; Wu, X. Enhanced Thermal Properties of Novel ShapeStabilized PEG Composite Phase Change Materials with Radial Mesoporous Silica Sphere for Thermal Energy Storage. Sci. Rep. 2015, 5, 12964.

(24) Li, Y.; Yu, S.; Chen, P.; Rojas, R.; Hajian, A.; Berglund, L. Cellulose Nanofibers Enable Paraffin Encapsulation and the Formation of Stable Thermal Regulation Nanocomposites. Nano Energy 2017, 34, 541-548.

(25) Thomas, R. J. Wood: Structure and Chemical Composition. Wood Technology: Chemical Aspects, 1977; pp 1-23.

(26) Fratzl, P.; Weinkamer, R. Nature's hierarchical materials. Prog. Mater. Sci. 2007, 52, 1263-1334.

(27) Speck, T.; Burgert, I. Plant Stems: Functional Design and Mechanics. Annu. Rev. Mater. Res. 2011, 41, 169-193.

(28) Li, Y.; Li, X.; Liu, D.; Cheng, X.; He, X.; Wu, Y.; Li, X.; Huang, Q. Fabrication and Properties of Polyethylene Glycol-Modified Wood Composite for Energy Storage and Conversion. BioResources 2016, 11, 7790-7802.

(29) Yang, H.; Wang, Y.; Yu, Q.; Cao, G.; Yang, R.; Ke, J.; Di, X.; Liu, F.; Zhang, W.; Wang, C. Composite Phase Change Materials with Good Reversible Thermochromic Ability in Delignified Wood Substrate for Thermal Energy Storage. Appl. Energy 2018, 212, 455-464.

(30) Vasco, D. A.; Salinas-Lira, C.; Barra-Reyes, I.; Elustondo, D. M. Kinematic Characterization of the Pressure-Dependent PCM Impregnation Process for Radiata Pine Wood Samples. Eur. J. Wood Wood Prod. 2018, 76, 1461-1469.

(31) ASTM D1003-13. Standard Test Method for Haze and Luminous Transmittance of Transparent Plastics; ASTM International: West Conshohocken, PA, 2013.

(32) Stamm, A. Effect of Polyethylene Glycol on the Dimensional Stability of Wood. For. Prod. J. 1959, 9, 375-381.

(33) Jeremic, D.; Cooper, P.; Heyd, D. PEG Bulking of Wood Cell Walls as Affected by Moisture Content and Nature of Solvent. Wood Sci. Technol. 2007, 41, 597-606.

(34) Bjurhager, I.; Ljungdahl, J.; Wallström, L.; Gamstedt, E. K.; Berglund, L. A. Towards Improved Understanding of PEGImpregnated Waterlogged Archaeological Wood: A Model Study on Recent Oak. Holzforschung 2010, 64, 243-250.

(35) Pandey, K. K. A study of chemical structure of soft and hardwood and wood polymers by FTIR spectroscopy. J. Appl. Polym. Sci. 1999, 71, 1969-1975.

(36) Kuroda, Y.; Kubo, M. CH2 Rocking Vibrations and the Structure of Polyethylene Glycols. J. Polym. Sci. 1959, 36, 453-459.

(37) Craig, D. Q. M.; Newton, J. M. Characterisation of Polyethylene Glycol Solid Dispersions Using Differential Scanning Calorimetry and Solution Calorimetry. Int. J. Pharm. 1991, 76, 17-24.

(38) Han, S.; Kim, C.; Kwon, D. Thermal/Oxidative Degradation and Stabilization of Polyethylene Glycol. Polymer 1997, 38, 317-323.

(39) Li, Y.; Fu, Q.; Yang, X.; Berglund, L. Transparent Wood for Functional and Structural Applications. Philos. Trans. R. Soc., A 2018, 376, 20170182.

(40) Emami, N.; Sjödahl, M.; Söderholm, K.-J. M. How Filler Properties, Filler Fraction, Sample Thickness and Light Source Affect Light Attenuation in Particulate Filled Resin Composites. Dent. Mater. 2005, 21, 721-730.

(41) Fink, S. Transparent Wood-A New Approach in the Functional Study of Wood Structure. Holzforschung 1992, 46, 403408. 